\title{
A Cross-Sectional Online Survey Identifies Subspecialty Differences in the Management of Pediatric Cataracts Associated with Uveitis
}

\author{
Samuel J. Carpentier · Jennifer L. Jung · Jennifer L. Patnaik • \\ Paula E. Pecen · Alan G. Palestine
}

Received: January 8, 2020 / Published online: March 10, 2020

(C) The Author(s) 2020

\begin{abstract}
Introduction: To determine if differences exist between pediatric ophthalmologists and uveitis ophthalmologists in the treatment of pediatric uveitic cataracts and placement of intraocular lenses.

Methods: Uveitis ophthalmologists and pediatric ophthalmologists were surveyed via an online poll regarding their therapeutic management of pediatric uveitic cataract and intraocular lens (IOL) placement.

Results: Sixty-two responses from uveitis ophthalmologists and 47 responses from pediatric ophthalmologists were recorded. According to $79 \%$ of all responses, uveitis was not a contraindication for primary IOL implantation in patients with controlled intraocular inflammation. Pediatric ophthalmologists were more likely to respond that the presence of chronic
\end{abstract}

Enhanced digital features To view enhanced digital features for this article go to https://doi.org/10.6084/ m9.figshare.11907261.

Electronic supplementary material The online version of this article (https://doi.org/10.1007/s40123$020-00245-\mathrm{x}$ ) contains supplementary material, which is available to authorized users.

S. J. Carpentier · J. L. Jung · J. L. Patnaik ·

P. E. Pecen · A. G. Palestine $(\varangle)$

Department of Ophthalmology, University of

Colorado School of Medicine, Aurora, CO, USA

e-mail: alan.palestine@cuanschutz.edu juvenile idiopathic arthritis-associated iridocyclitis, pars planitis, or recurrent acute anterior uveitis is a contraindication for primary IOL implantation in pediatric cases with full control of intraocular inflammation. There was no consensus within either specialty with regard to the preferred IOL material for lens implantation. Uveitis ophthalmologists were more likely to report the use of intravenous and intravitreal steroids for perioperative treatment. In cataract surgery for a child with recurrent acute anterior uveitis, a higher percentage of uveitis ophthalmologists $(71 \%)$ than pediatric ophthalmologists $(50 \%)$ responded that the posterior capsule should be primarily opened. A higher percentage of uveitis ophthalmologists also stated that anterior vitrectomy should be performed at the time of cataract surgery in all three uveitis types.

Conclusions: Pediatric ophthalmologists and uveitis ophthalmologists have similar approaches to the management of pediatric uveitic cataract removal and IOL insertion, but several differences remain between these subspecialties. Continued collaboration between the subspecialties would be helpful to better develop consistent criteria to improve patient care.

Keywords: Cataract removal; Inflammation; Intraocular lens; Pediatric ophthalmologists; Uveitis; Uveitis ophthalmologists 


\section{Key Summary Points}

\section{Why carry out this study?}

Pediatric uveitis is a significant cause of ocular morbidity that can result in permanent visual loss.

Pediatric uveitis and the use of steroids can lead to cataract development.

The hypothesis of this study was that there may be differences in how uveitis ophthalmologists and pediatric ophthalmologists treat uveitic pediatric cataract removal and IOL placement.

What was learned from the study?

Pediatric ophthalmologists and uveitis ophthalmologists have similar approaches to the management of pediatric IOL insertion, but several differences remain between these subspecialties.

When considering chronic JIA-associated iridocyclitis, pars planitis, or recurrent acute anterior uveitis, uveitis ophthalmologists were less likely than pediatric ophthalmologists to respond that any of these conditions were contraindications for IOL implantation after cataract removal.

Continued collaboration between these subspecialties would be helpful to better develop consistent criteria to improve patient care.

\section{INTRODUCTION}

Pediatric uveitis is a significant cause of ocular morbidity with severe complications that can potentially result in permanent visual loss. Both pediatric uveitis and the use of steroids to treat inflammatory disease can lead to cataract development, which is seen in up to $70 \%$ of pediatric patients with chronic uveitis $[1,2]$. For these patients, cataract surgery may be accompanied by increased inflammation. Several studies have shown that perioperative control of uveitis results in improved visual acuity [1, 3-8]; however, primary intraocular lens (IOL) insertion in cases of pediatric uveitic cataract is still controversial [4, 5, 7-9].

Pediatric uveitis can be treated by uveitis ophthalmologists or pediatric ophthalmologists. It is recognized that there are differences between specialties in the management of conditions [10-16], so we hypothesized that there may be differences in how uveitis ophthalmologists and pediatric ophthalmologists treat uveitic pediatric cataract removal and IOL placement. To explore this hypothesis, we created an online survey to assess the management strategies of uveitis ophthalmologists and pediatric ophthalmologists.

\section{METHODS}

This study was approved by the Colorado Multiple Institution Review Board (COMIRB 19-0403) and conformed to the requirements of the United States Health Insurance Portability and Privacy Act. It conformed with the Helsinki Declaration of 1964, as revised in 2013, concerning human and animal rights, and Springer's policy concerning informed consent was followed. We developed an online survey to poll the responses of uveitis ophthalmologists and pediatric ophthalmologists to hypothetical vignettes of pediatric uveitis patients with cataracts (Fig. S1 in the Electronic supplementary material, ESM). American Uveitis Society (AUS) members who were participants in the AUS discussion board and American Association for Pediatric Ophthalmology and Strabismus members were surveyed. Respondents were asked to identify as pediatric ophthalmologists or uveitis ophthalmologists in addition to reporting their number of years and region of medical practice. This survey included a series of questions regarding the treatment of chronic juvenile idiopathic arthritis (JIA)-associated iridocyclitis, pars planitis, and recurrent acute anterior uveitis. These questions queried if the type of uveitis is a contraindication for primary 
IOL implantation, the minimum amount of time of quiescent inflammation before it is appropriate to proceed with cataract extraction and IOL insertion, the minimum age at which cataract extraction and IOL insertion is appropriate, whether the posterior capsule should be primarily opened or left untouched, and if an anterior vitrectomy should be performed at the time of cataract surgery. Participants were also asked about the management of a patient with quiet uveitis who was aphakic from previous surgery and contact lens intolerant. Additional questions explored responses to whether the etiology of uveitis is important for cataract extraction with IOL insertion, which type of IOL was best, if the capsular bag or sulcus was a better location for primary IOL placement in pediatric patients with uveitis, the preoperative visual acuity that is required for cataract extraction with IOL insertion, and if implantation of IOL simultaneously with lens removal was preferable to postponing the implantation of IOL until after cataract removal. Respondents were asked if unilateral or bilateral uveitis affected IOL implantation, if the presence of amblyopia is a contraindication for IOL implantation, and about the modalities they used to control inflammation perioperatively.

We used Research Electronic Data Capture (REDCap) to distribute a link to the questionnaire. Two attempts were made to reach 277 members of the American Uveitis Society email discussion board and 923 pediatric ophthalmologists via the American Association of Pediatric Ophthalmology Listserv. Data were collected voluntarily and anonymously from April 7 through April 30, 2019.

Descriptive statistics included percentages for categorical variables. Potential differences between pediatric ophthalmologists and uveitis ophthalmologists were compared, as were physicians with less than 20 years of experience versus those with 20 or more years of experience, using chi-square testing or Fisher's exact testing. $p$ values less than 0.05 were considered statistically significant. All analyses were performed using SAS software (version 9.4, SAS Institute Inc., Cary, NC, USA).

\section{RESULTS}

A total of 109 physicians responded to the survey questions, including 62/277 (22\% response rate) uveitis ophthalmologists and 47/923 (5\% response rate) pediatric ophthalmologists. Physician years of experience and the region of practice did not differ significantly between the pediatric and uveitis ophthalmologists ( $p$ $=0.325$ and $p=0.754$, respectively). Various regions of the United States were well represented in this survey, and $21 \%$ of the respondents indicated that they practice medicine outside of the United States.

A majority of the respondents reported that uveitis was not a contraindication for primary IOL implantation (Table 1). The responses were not statistically different when asked if chronic JIA-associated iridocyclitis or recurrent acute anterior uveitis was a contraindication for primary IOL implantation $(p=0.496$ and $p$ $=0.155$, respectively). Subspecialties differed significantly ( $p=0.003$ ) in their choices for the treatment of pars planitis, with $100 \%$ of the uveitis ophthalmologists responding that pars planitis was not a contraindication for primary IOL implantation, compared to $85.1 \%$ of pediatric ophthalmologists. Overall, uveitis ophthalmologists were less likely to respond that any of the three inflammatory diseases were a contraindication for primary IOL insertion in pediatric cases with control of intraocular inflammation ( $p=0.053)$.

For both subspecialties, most preferred to place the primary IOL in the capsular bag rather than the sulcus $(85.1 \%$ of pediatric ophthalmologists and $96.8 \%$ of uveitis ophthalmologists). There was no consensus regarding optimal IOL type after cataract removal in pediatric patients with uveitis; hydrophobic acrylic IOLs were the type of lens most commonly selected by respondents (36.2\% of pediatric ophthalmologists and $54.8 \%$ of uveitis ophthalmologists).

There was no significant difference between the two subspecialties for the threshold of preoperative visual acuity required for cataract extraction in pediatric uveitic patients younger than 7 years old. Uveitis ophthalmologists and pediatric ophthalmologists also had similar 
Table 1 Survey responses regarding the management of cataract extraction and IOL implantation in pediatric patients with uveitis

\begin{tabular}{|c|c|c|c|}
\hline & $\begin{array}{l}\text { Pediatric } \\
\text { ophthalmologists }\end{array}$ & $\begin{array}{l}\text { Uveitis } \\
\text { ophthalmologists }\end{array}$ & $\begin{array}{l}\text { Chi square or } \\
\text { Fisher's exact } \\
p \text { value }\end{array}$ \\
\hline Number of respondents & 47 & 62 & - \\
\hline \multicolumn{4}{|l|}{$\begin{array}{l}\text { In pediatric cases with control of intraocular } \\
\text { inflammation, the following are contraindications to } \\
\text { IOL implantation: }\end{array}$} \\
\hline Chronic JIA-associated iridocyclitis & $5(10.6 \%)$ & $4(6.4 \%)$ & 0.496 \\
\hline Pars planitis & $7(14.9 \%)$ & $0(0.0 \%)^{\mathrm{a}}$ & 0.003 \\
\hline Recurrent acute anterior uveitis & $10(21.3 \%)$ & $7(11.3 \%)$ & 0.155 \\
\hline Any of these three are contraindications & $14(29.8)$ & $9(14.5)$ & 0.053 \\
\hline $\begin{array}{l}\text { In a pediatric patient, the etiology of uveitis matters for } \\
\text { the decision for cataract extraction with IOL insertion } \\
\text { if the inflammation is well-controlled for three months }\end{array}$ & $27(57.4 \%)$ & $38(62.3 \%)^{\mathrm{b}}$ & 0.610 \\
\hline \multicolumn{4}{|l|}{$\begin{array}{l}\text { Which type of IOL is best for IOL insertion after } \\
\text { cataract removal in pediatric patients with uveitis? }\end{array}$} \\
\hline Hydrophobic acrylic & $17(36.2 \%)$ & $34(54.8 \%)$ & \\
\hline Hydrophilic acrylic & $9(19.2 \%)$ & $14(22.6 \%)$ & \\
\hline Silicone & $3(6.4 \%)$ & $0(0.0 \%)$ & \\
\hline Poly methyl methacrylate (PMMA) & $6(12.8 \%)$ & $4(6.4 \%)$ & \\
\hline Heparin-coated PMMA & $4(8.5 \%)$ & $4(6.4 \%)$ & \\
\hline No response & $8(17.0 \%)$ & $6(9.7 \%)$ & 0.123 \\
\hline \multicolumn{4}{|l|}{$\begin{array}{l}\text { Where should the primary IOL be placed in a pediatric } \\
\text { patient with uveitis? }\end{array}$} \\
\hline Capsular bag & $40(85.1 \%)$ & $60(96.8 \%)$ & \\
\hline Sulcus & $4(8.5 \%)$ & $1(1.6 \%)$ & \\
\hline Uveitis is a contraindication & $3(6.4 \%)$ & $1(1.6 \%)$ & 0.087 \\
\hline \multicolumn{4}{|l|}{$\begin{array}{l}\text { What is the pre-operative visual acuity required for } \\
\text { cataract extraction with IOL insertion in } \\
\text { patients }<7 \text { years old with uveitis? }\end{array}$} \\
\hline Worse than $20 / 40$ & $17(37.0 \%)$ & $34(55.7 \%)$ & \\
\hline Worse than $20 / 80$ & $24(52.2 \%)$ & $23(37.7 \%)$ & \\
\hline Worse than $20 / 200$ & $5(10.9 \%)$ & $4(6.6 \%)$ & \\
\hline No response & 1 & 1 & 0.152 \\
\hline
\end{tabular}


Table 1 continued

\begin{tabular}{lll}
$\begin{array}{l}\text { Pediatric } \\
\text { ophthalmologists }\end{array}$ & $\begin{array}{l}\text { Uveitis } \\
\text { ophthalmologists }\end{array}$ & $\begin{array}{l}\text { Chi square or } \\
\text { Fisher's exact } \\
p \text { value }\end{array}$ \\
\hline
\end{tabular}

What is the pre-operative visual acuity required for

cataract extraction with IOL insertion in

patients $>7$ years old with uveitis?

Worse than $20 / 40$

$\begin{array}{ll}23(50.0 \%) & 32(52.5 \%) \\ 21(45.6 \%) & 24(39.3 \%) \\ 2(4.4 \%) & 5(8.2 \%) \\ 1 & 1\end{array}$

No response

After cataract removal, is it more appropriate to implant the IOL simultaneously with lens removal or postpone implantation of the IOL after a period of contact lens use after lens removal?

Implant simultaneously

$42(89.4 \%)$

$5(10.6 \%)$

$20(42.6 \%)$

Unilateral or bilateral uveitis affects IOL implantation decision in a pediatric patient with well-controlled uveitis

Presence of amblyopia is a contraindication to proceed with IOL implantation in a pediatric patient with well-controlled uveitis

Modalities used to control inflammation perioperatively:

Sub-Tenon's steroid injection

$32(68.1 \%)$

$44(71.0 \%)$

0.746

Intravitreal steroid injection

$14(29.8 \%)$

$40(64.5 \%)$

0.003

Intravenous steroid

$16(34.0 \%)$

$37(59.7 \%)$

0.008

Oral steroid
$52(83.9 \%)$

$p$ values $<0.05$ are significant and are shown in bold

a Three people did not respond to this question

b One person did not respond to this question

thresholds of preoperative visual acuity required for cataract extraction in pediatric uveitic patients older than 7 years old.

Only small percentages of the pediatric ophthalmologists (4.3\%) and uveitis ophthalmologists (6.4\%) responded that the presence of amblyopia is a contraindication for proceeding with IOL implantation in a pediatric patient with well-controlled uveitis.

For perioperative adjunctive treatment, a majority of each subspecialty reported using subTenon's steroid injections and oral steroids to control inflammation perioperatively. However, the subspecialties differed significantly in the use of intravenous and intravitreal steroids, with uveitis ophthalmologists being more likely to use both modalities than pediatric ophthalmologists ( $p=0.008$ and $p=0.003$, respectively). 


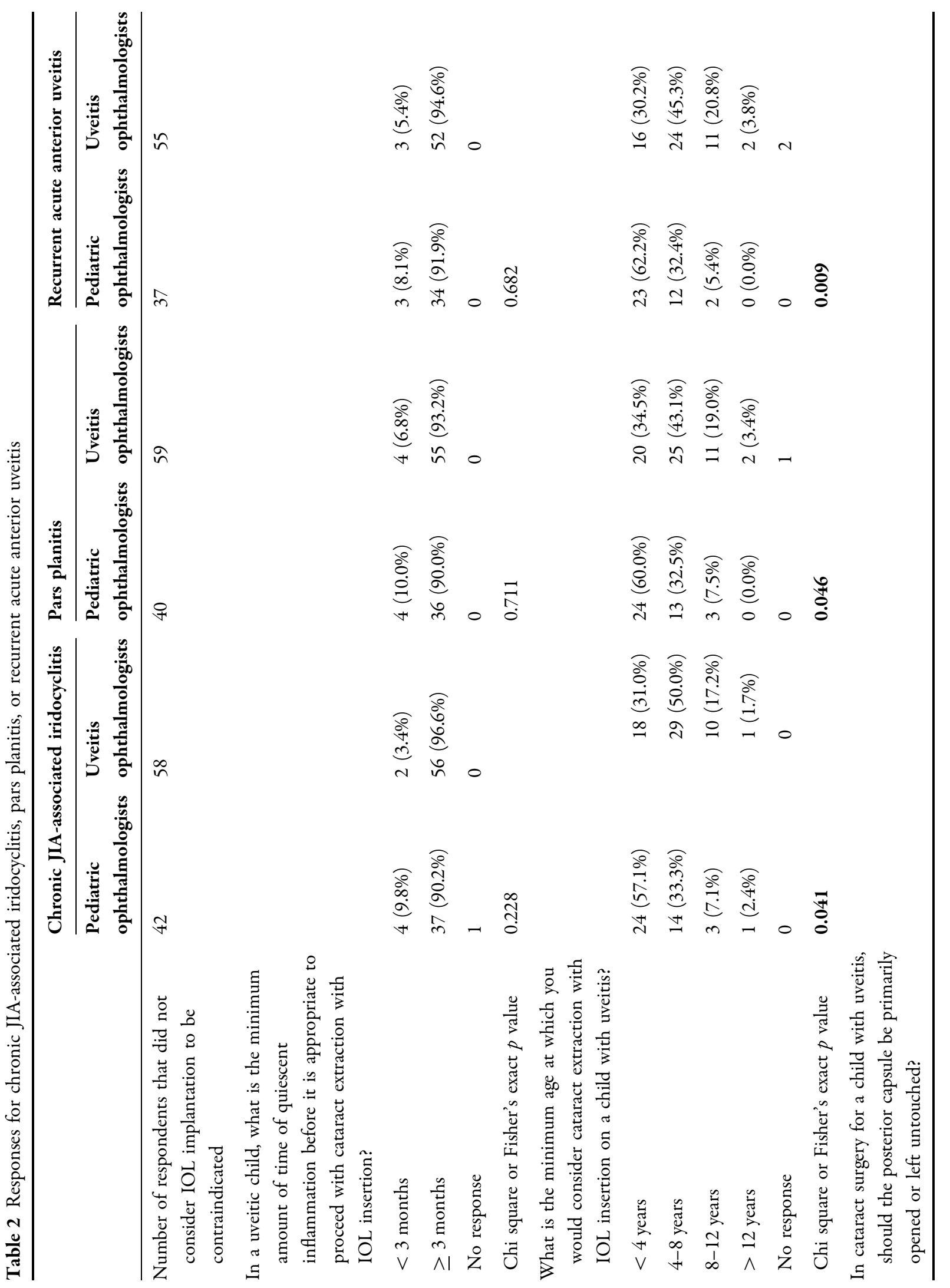




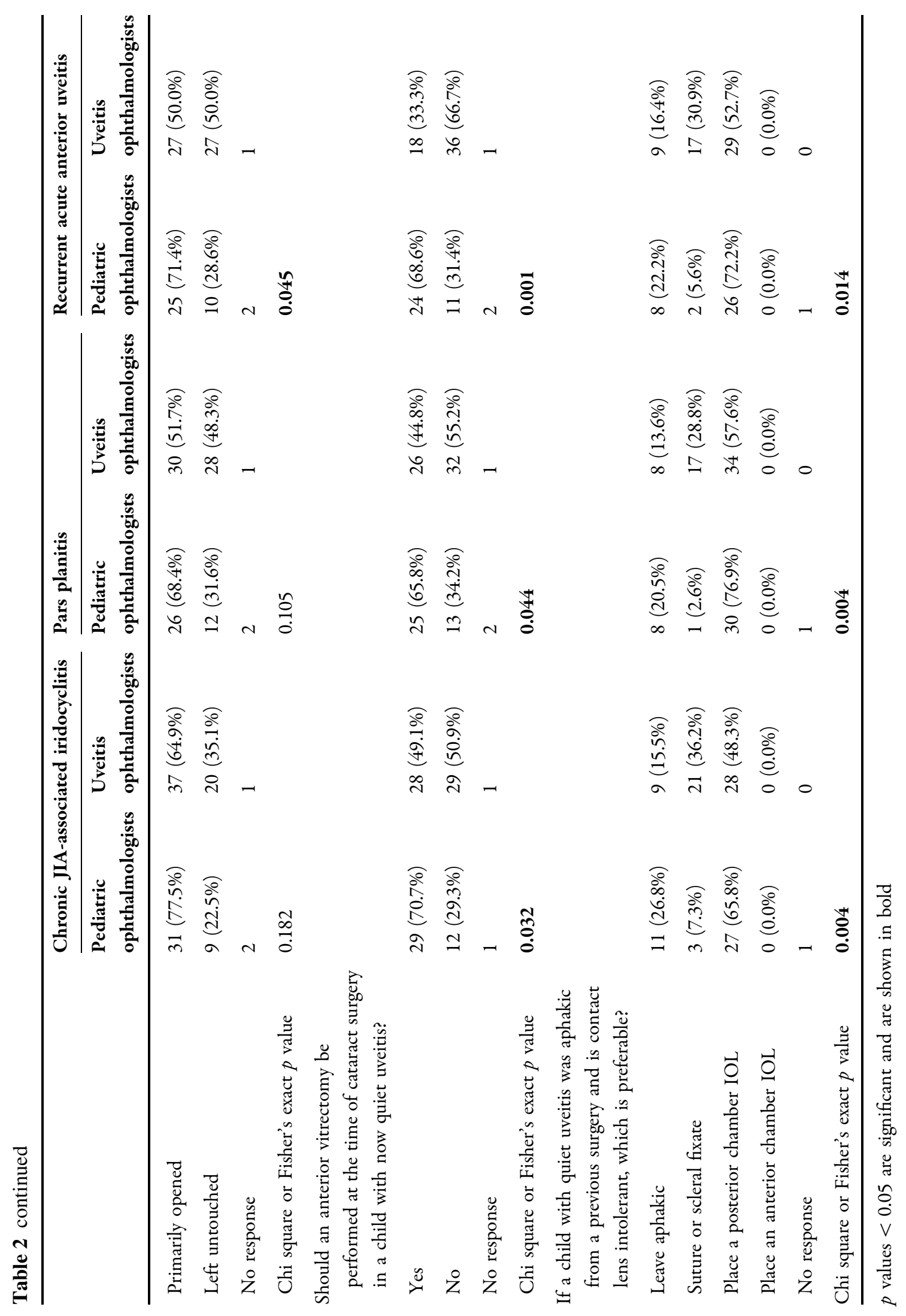


Table 2 compares the responses of pediatric ophthalmologists and uveitis ophthalmologists who did not consider chronic JIA-associated iridocyclitis, pars planitis, or recurrent acute anterior uveitis to be a contraindication for surgery. More than $90 \%$ of all subspecialists answered that $\geq 3$ months was the minimum amount of time of quiescent inflammation before proceeding with cataract extraction and IOL insertion for all three types of uveitis (Table 2).

There were significant differences between pediatric ophthalmologists and uveitis ophthalmologists with regard to the minimum age at which the respondent would consider cataract extraction with IOL insertion in a child with uveitis. Compared to uveitis ophthalmologists, more pediatric ophthalmologists responded that $<4$ years old was the minimum age for cataract extraction with IOL insertion in a child with chronic JIA-associated iridocyclitis, pars planitis, or recurrent acute anterior uveitis $(p$ $=0.041, p=0.046$, and $p=0.009$, respectively).

For chronic JIA-associated iridocyclitis and pars planitis, the majority of pediatric ophthalmologists and uveitis ophthalmologists responded that the posterior capsule should be primarily opened. However, for recurrent acute anterior uveitis, pediatric ophthalmologists (71.4\%) were more likely than uveitis ophthalmologists $(50 \%, p=0.045)$ to choose to open the posterior capsule primarily. For all three types of uveitis, pediatric ophthalmologists were more likely than uveitis ophthalmologists $(p=0.032, p=0.044$, and $p=0.001$ for chronic JIA-associated iridocyclitis, pars planitis, and recurrent acute anterior uveitis, respectively) to choose to perform an anterior vitrectomy.

For the vignette of a child with quiet uveitis who was aphakic from a previous surgery and contact lens intolerant, treatment choices differed between the two subspecialties ( $p=0.004$, $p=0.004$, and $p=0.014$ for chronic JIA-associated iridocyclitis, pars planitis, and recurrent acute anterior uveitis, respectively). While both subspecialty groups preferred to place a posterior chamber IOL, pediatric ophthalmologists were more likely to choose aphakia over sulcus or scleral-fixated IOLs.

When stratified by years of practice, there were no significant differences in treatment decisions between physicians who had practiced for less than 20 years and physicians who had practiced for 20 years or more.

\section{DISCUSSION}

This cross-sectional online survey demonstrated the presence of subspecialty management differences for uveitic cataracts in pediatric patients that are consistent with our hypothesis. Additionally, the results of this study help to identify current treatment decisions made by uveitis ophthalmologists and pediatric ophthalmologists for pediatric cataracts associated with uveitis. Some of these differences between the subspecialties were statistically significant while wide variations in treatment options and decisions were also seen for both subspecialties. For example, there was no consensus in either subspecialty regarding optimal IOL type after cataract removal in pediatric patients with uveitis.

In our vignettes concerning chronic JIA-associated iridocyclitis, pars planitis, or recurrent acute anterior uveitis, pediatric ophthalmologists were more likely than uveitis ophthalmologists to respond that pars planitis was a contraindication for IOL implantation after cataract removal. This is interesting, since pars planitis is associated with the least risk for developing synechiae and other IOL-related complications among the three types of uveitis. When all three types of uveitis were considered, uveitis ophthalmologists were less likely to respond that any of these conditions were contraindications for IOL implantation after cataract removal. It is known that appropriate control of intraocular inflammation is an important prognostic factor for cataract surgery $[3,17]$. Uveitis ophthalmologists may feel more comfortable when they have decided that intraocular inflammation is well controlled and it would therefore be beneficial to operate on these patients. Multiple factors need to be taken into consideration before deciding for or against 
IOL insertion in these patients, and additional studies would help to inform clinical decisionmaking.

Our survey responses indicate there is no consensus among uveitis ophthalmologists or pediatric ophthalmologists with regard to the preferred IOL material for lens implantation after cataract removal. This is interesting, as there appears to be a concern that an IOL may trigger intraocular inflammation in uveitic eyes [17]. Our results are consistent with a Cochrane review which concluded that there was uncertainty regarding the optimal IOL type during uveitic cataract surgery [18].

Pediatric ophthalmologists were more likely to consider a younger age for cataract extraction with IOL insertion in a child with uveitis. This may reflect a higher level of comfort of pediatric ophthalmologists with performing surgery on younger children. Alternatively, our results could indicate that uveitis ophthalmologists believe that inflammatory responses may be more difficult to manage in younger patients.

For perioperative management, both specialties commonly used sub-Tenon's steroid injections and oral steroids. However, uveitis ophthalmologists were more likely to utilize intravitreal steroid injections and intravenous steroids compared to pediatric ophthalmologists. Intravitreal steroid injections may be more frequently used by uveitis ophthalmologists in general. Intravenous intraoperative steroids may be a useful addition that can be beneficial for and easily employed in all uveitis patients undergoing intraocular surgery. Our institution typically administers intravenous Solu-Medrol $1 \mathrm{mg} / \mathrm{kg}$ to pediatric patients with uveitis who are undergoing cataract surgery.

The majority of studies conducted on pediatric uveitic cataract management have been small retrospective studies [1, 4-8, 19, 20], which have not been sufficient to derive clear recommendations for lens implantation in pediatric patients with uveitic cataracts. However, the present study indicates that there are several clinical scenarios in which there is considerable agreement among pediatric ophthalmologists and uveitis ophthalmologists. Most of the responses indicated that a visual acuity of 20/80 would be appropriate for cataract extraction and IOL insertion in pediatric patients with uveitis, but a substantial number of surgeons would also consider eyes worse than $20 / 40$. The vast majority of both uveitis and pediatric ophthalmologists also indicated that the presence of amblyopia was not a contraindication for proceeding with IOL implantation in a pediatric patient with wellcontrolled uveitis. Over $90 \%$ of all respondents also agreed that 3 months is the minimum amount of time of controlled inflammation before it is appropriate to proceed with cataract removal and IOL insertion for chronic JIA-associated iridocyclitis, pars planitis, or recurrent acute anterior uveitis. A high percentage of the responses indicated that implantation of the IOL simultaneously with lens removal is preferable to postponing IOL implantation until after lens removal. These results contrast with those obtained in a retrospective study which found that secondary IOL implantation after cataract removal in pediatric patients with chronic JIA-related uveitis had a lower incidence of secondary glaucoma [21].

In the vignette concerning IOL placement location, the majority of the respondents preferred to place the primary IOL in the capsular bag rather than the sulcus. This finding contrasts with a previous study which found that ciliary sulcus fixation may reduce the risk of postoperative posterior synechiae [9]. The authors of the retrospective study suggested that IOL placement in the sulcus may prevent adhesions because the IOL then serves as a barrier between the iris and lens capsule remnants. While all 12 of the patients in the study were adults, all of the eyes were thought to be at a high risk for posterior synechia due to preexisting posterior synechiae, damage to the iris visible in a preoperative slit-lamp examination, a specific diagnosis associated with posterior synechiae formation, or a combination of those factors.

Limitations of this study that may have introduced bias include a small sample size and a low response rate. Additionally, online engagement may not be representative of all practicing pediatric or uveitis ophthalmologists. Our survey was also largely distributed to physicians practicing in academia, which may 
make these results less generalizable to the broader field of ophthalmology.

\section{CONCLUSIONS}

The results of this study indicate that uveitis ophthalmologists and pediatric ophthalmologists often agree on many practices regarding pediatric uveitic cataract removal and IOL insertion. However, management differences between these subspecialties persist. The data obtained in this work suggest that it may be beneficial for these subspecialties to communicate and collaborate to improve patient care.

\section{ACKNOWLEDGEMENTS}

We express our deep appreciation to the participants of this study.

Funding. This study was supported in part by a challenge grant from Research to Prevent Blindness, New York, NY to the University of Colorado Department of Ophthalmology. No funding or sponsorship was received for the publication of this article.

Authorship. All named authors meet the International Committee of Medical Journal Editors (ICMJE) criteria for authorship for this article, take responsibility for the integrity of the work as a whole, and have given their approval for this version to be published.

Disclosures. Samuel Carpentier, Jennifer Jung, Jennifer Patnaik, Paula Pecen, and Alan Palestine declare that they have no conflict of interest.

Compliance with Ethics Guidelines. This study was approved by the Colorado Multiple Institution Review Board (COMIRB 19-0403) and conformed to the requirements of the United States Health Insurance Portability and Privacy Act. This study conformed with the Helsinki Declaration of 1964, as revised in 2013, concerning human and animal rights, and
Springer's policy concerning informed consent was followed.

Data Availability. The datasets analyzed during the current study are available from the corresponding author on reasonable request.

Open Access. This article is licensed under a Creative Commons Attribution-NonCommercial 4.0 International License, which permits any non-commercial use, sharing, adaptation, distribution and reproduction in any medium or format, as long as you give appropriate credit to the original author(s) and the source, provide a link to the Creative Commons licence, and indicate if changes were made. The images or other third party material in this article are included in the article's Creative Commons licence, unless indicated otherwise in a credit line to the material. If material is not included in the article's Creative Commons licence and your intended use is not permitted by statutory regulation or exceeds the permitted use, you will need to obtain permission directly from the copyright holder. To view a copy of this licence, visit http:// creativecommons.org/licenses/by-nc/4.0/.

\section{REFERENCES}

1. Ganesh SK, Mistry S. Phacoemulsification with intraocular lens implantation in pediatric uveitis: a retrospective study. Ocul Immunol Inflamm. 2018;26(2):305-12.

2. Majumder PD, Biswas J. Pediatric uveitis: an update. Oman J Ophthalmol. 2013;6(3):140-50.

3. Mehta S, Linton MM, Kempen JH. Outcomes of cataract surgery in patients with uveitis: a systematic review and meta-analysis. Am J Ophthalmol. 2014;158(4):676-92.e7.

4. Fan DS, Chan CK, Cheng AC, Rao SK, Yu CB, Lam DS. Multistage approach to uveitic cataract management in children. J Pediatr Ophthalmol Strabismus. 2006;43(3):172-5.

5. Grajewski RS, Zurek-Imhoff B, Roesel M, Heinz C, Heiligenhaus A. Favourable outcome after cataract surgery with IOL implantation in uveitis associated 
with juvenile idiopathic arthritis. Acta Ophthalmol. 2012;90(7):657-62.

6. Nemet AY, Raz J, Sachs D, Friling R, Neuman R, Kramer M, et al. Primary intraocular lens implantation in pediatric uveitis: a comparison of 2 populations. Arch Ophthalmol. 2007;125(3):354-60.

7. Terrada C, Julian K, Cassoux N, Prieur AM, Debre M, Quartier $\mathrm{P}$, et al. Cataract surgery with primary intraocular lens implantation in children with uveitis: long-term outcomes. J Cataract Refract Surg. 2011;37(11):1977-83.

8. Pålsson S, Nyström A, Sjödell L, Jakobsson G, Byhr $\mathrm{E}$, Andersson Grönlund $\mathrm{M}$, et al. Combined phacoemulsification, primary intraocular lens implantation, and pars plana vitrectomy in children with uveitis. Ocul Immunol Inflamm. 2015;23(2): 144-51.

9. Holland GN, Van Horn SD, Margolis TP. Cataract surgery with ciliary sulcus fixation of intraocular lenses in patients with uveitis. Am J Ophthalmol. 1999;128(1):21-30.

10. Fredrickson JS, Holmes J, Cathcart JN, Lynch AM, Kolfenbach JR, Palestine AG. Specialty management differences of syphilis and toxoplasmosis surrounding pregnancy: a prospective cross-sectional study. J Ophthalmic Inflamm Infect. 2018;8(1):10.

11. Ariane MM, Ploussard G, Rebillard X, Malavaud B, Rischmann P, Hennequin C, et al. Differences in practice patterns between urologists and radiation oncologists in the management of localized prostate cancer: a cross-sectional survey. World J Urol. 2015;33(11):1741-7.

12. Mohan GC, Lio PA. Comparison of dermatology and allergy guidelines for atopic dermatitis management. JAMA Dermatol. 2015;151(9):1009-13.
13. Jollis JG, DeLong ER, Peterson ED, Muhlbaier LH, Fortin DF, Califf RM, et al. Outcome of acute myocardial infarction according to the specialty of the admitting physician. $\mathrm{N}$ Engl $\mathrm{J}$ Med. 1996;335(25):1880-7.

14. Palestine AG, Kolfenbach JR, Ozzello DJ. Rheumatologists and ophthalmologists differ in treatment decisions for ocular Behçet disease. J Clin Rheumatol. 2016;22(6):316-9.

15. Ozzello DJ, Kolfenbach JR, Palestine AG. Uveitis specialists and rheumatologists select different therapies for idiopathic non-necrotizing anterior scleritis. Ophthalmol Ther. 2016;5(2):245-52.

16. Palestine AG, Singh JK, Kolfenbach JR, Ozzello DJ. Specialty practice and cost considerations in the management of uveitis associated with juvenile idiopathic arthritis. J Pediatr Ophthalmol Strabismus. 2016;53(4):246-51.

17. Phatak S, Lowder C, Pavesio C. Controversies in intraocular lens implantation in pediatric uveitis. J Ophthalmic Inflamm Infect. 2016;6(1):12.

18. Leung TG, Lindsley K, Kuo IC. Types of intraocular lenses for cataract surgery in eyes with uveitis. Cochrane Database Syst Rev. 2014;3:CD007284.

19. BenEzra D, Cohen E. Cataract surgery in children with chronic uveitis. Ophthalmology. 2000;107(7): 1255-60.

20. Guindolet D, Dureau P, Terrada C, Edelson C, Barjol A, Caputo G, et al. Cataract surgery with primary lens implantation in children with chronic uveitis. Ocul Immunol Inflamm. 2018;26(2):298-304.

21. Magli A, Forte R, Rombetto L, Alessio M. Cataract management in juvenile idiopathic arthritis: simultaneous versus secondary intraocular lens implantation. Ocul Immunol Inflamm. 2014;22(2): 133-7. 